\title{
EAl Endorsed Transactions

\section{Role and Performance of Different Traditional Classification and Nature-Inspired Computing Techniques in Major Research Areas}

\author{
Samriti Sharma ${ }^{1} *$, Gurvinder Singh ${ }^{1}$, Dhanpreet Singh $^{2}$ \\ ${ }^{1}$ Department of Computer Science, GNDU Amritsar. \\ ${ }^{2}$ Centre for IT solution, GNDU Amritsar.
}

\section{Abstract}

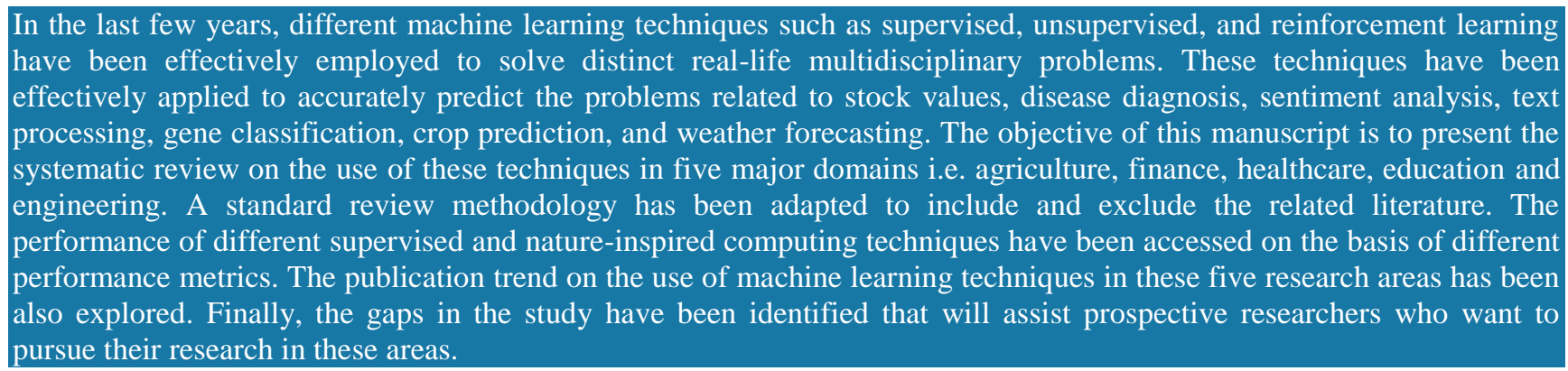

Keywords: Machine Learning, Agriculture, Engineering, Education, Stock Forecasting, Disease Diagnosis.

Received on 09 March 2019, accepted on 12 April 2019, published on 16 April 2019

Copyright (C) 2019 Samriti Samriti et al., licensed to EAI. This is an open-access article distributed under the terms of the Creative Commons Attribution license (http://creativecommons.org/licenses/by/3.0/), which permits unlimited use, distribution and reproduction in any medium so long as the original work is properly cited.

doi: 10.4108/eai.13-7-2018.158419

"Corresponding author. Email: smritignduphd@gmail.com

\section{Introduction}

Machine Learning(ML) is one of the major multidisciplinary research areas. As per Stanford University, Machine Learning is defined as a science that makes computer to perform some intelligent activities based upon existing data and without being explicitly programmed[1]. Machine Learning has been used in a wide sphere of life. There are three main categories of machine learning called supervised learning, unsupervised learning and reinforcement learning[2]. These techniques have been effectively used to solve a wide variety of classification, clustering and prediction problems. In supervised learning, the inputs are labeled and these labels are the desired outputs. These techniques assist in the data classification process. Disease diagnosis, stock prediction, sentiment analysis are some of the major application areas for supervised learning techniques. Traditionally, different techniques like naïve Bayes, decision tree, random forest and support vector machine have been dominantly used to solve different data classification problems. On the contrary, an unsupervised learning technique also known as clustering techniques deals with unlabeled data. No extra information is provided for grouping the data that's why these are called unsupervised techniques. Reinforcement learning is concerned with the behavior of software agents. There are some functions associated with these agents and they perform their operations in the specified environment to achieve the reward[3].

In the last few years, exponential growth in the use of machine learning techniques has been observed. Different machine learning techniques have been 
employed to solve variety of problems related to engineering[4], finance[5], medical science[6][7], weather forecasting[8], education[9], transportation[10], robotics[11] and agriculture[12]. Figure1 represents major applications of these techniques.

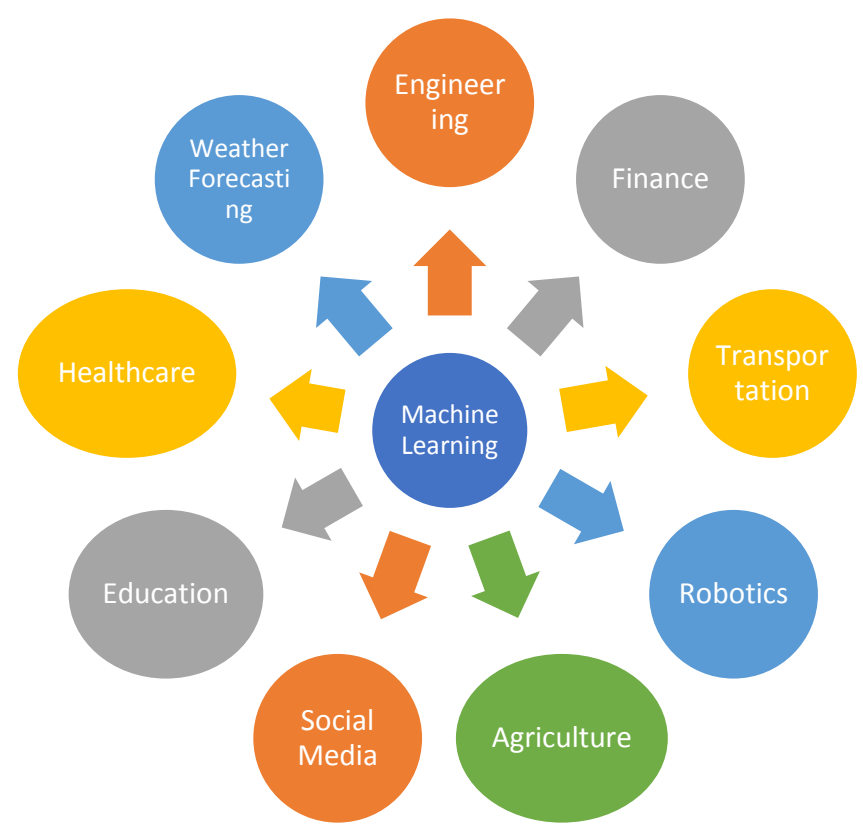

Figure1: Applications of Machine Learning

The intention of this research work is to present a systematic review of the role and performance of different machine learning techniques in five major research areas viz. agriculture, finance, healthcare, education, and engineering. Moreover, the publication trend of supervised and nature-inspired computing techniques used in these five research areas have been explored to determine the rate of publication of these two techniques in solving the real-life problems of these five major domains. After exploring different indexing databases, it has been found that several review articles have been written on the use of machine learning in different applications. Some of the major objectives of this study are:

- To briefly introduce the machine learning techniques.

- To accentuate the least and the most explored research domains by machine learning techniques.

- To present and analyze the role of machine learning in five major research areas(agriculture, finance, healthcare, education, and engineering)

- To explore the general publication trend of machine learning techniques.

- To find and present the rate of publication of natureinspired computing techniques in agriculture, finance, healthcare, education, and engineering.

Section 2 represents related works. Review methodology is presented in Section 3. The role and performance of machine learning techniques in five different areas are given in Section 4. Section 5 depicts the publication trend of related articles. Finally, the concluding remarks are presented in Section 6.

\section{Related Works}

In the last few decades, several review articles on the machine learning techniques and their applications have been published. Some of the studies are briefly introduced below:

Kim et al.[13] have reviewed ten different machine learning based manuscripts. However, they haven't specified any inclusion/exclusion criteria for their study. No significant findings and suitable future directions have been mentioned. Liakos et al.[12] have studied more than a hundred manuscripts related to the use of ML techniques in agriculture. It is an extensive study including the brief introduction of various classifiers and an explicitly stated review methodology. Subhadra Mishra et al.[14] have presented a review paper on the applications of machine learning techniques in crop production. No significant findings and future directions for the prospective researchers have been highlighted. Fan Cai et al.[15] have surveyed distinct clustering techniques for the analysis of financial data. Lin et al.[5]have reviewed different related articles to determine the data mining techniques which are periodically used in distinct business applications. Future directions are explicitly mentioned. Vivek Rajput et al.[16] have reviewed only eighteen articles related to stock market prediction using data mining and sentiment analysis. No significant details are generated in the study. Wei-Yang Lin et al[17] have performed an extensive review on the various machine learning techniques for bankruptcy prediction and credit scoring. Significant findings are provided by the authors for the practitioners which are interested to pursue their research in the related field. Ashish Sharma et al.[18] have discussed only regression techniques for stock market prediction. No significant future suggestions are mentioned. Kaur and Sharma[19] have presented an extensive analysis of data mining and soft computing techniques for mining diabetic patients. A systematic approach was used while selecting and filtering the article for their review. The authors concluded that in the last decade, a significant rise in the use of data mining and soft computing techniques for early diagnosis of diabetes has been found. Additionally, there is still a need for smart and intelligent diabetes diagnostic framework. Kaur and Sharma suggested combining machine learning and soft computing techniques with the Internet of Things, ontology and information theory for more precise diabetic classification results. Shubham Bind[20] et al. have presented a survey of different machine learning approaches used for Parkinson disease. Authors have also presented a systematic summary of use of machine learning techniques in diagnosing Parkinson disease by different researchers in the literature. But authors have not presented systematic review methodology adopted by 
them during their study. In 2018 Kaur et al.[21]have proposed big data and machine learning based diagnostic system model. There are four layers of the model. ML layer is responsible for disease diagnosis. Data security layers assist in providing security to the data. Different security techniques like activity monitoring, granular access control, PAM, OTP etc. have been used. Data storage layer provides the facility to store different types of data. Data source layer provide different source for data analysis. Divya Tomar et al.[7] have explored the various applications of data mining approaches in healthcare domain. Authors have explained different classification and clustering techniques along with their merits and de-merits and brief summary of machine learning techniques used in healthcare applications and the future directions for the other researchers are also presented. Shweta H.Jambukia et al.[22] have presented a detailed review on the classification of ECG(Electrocardiogram) signals. Authors have also discussed the various ECG databases, pre-processing techniques and issues involved in ECG classification. They have observed that neural networks give better results for ECG classification. Meherwar Fatima et al.[2] have presented a contigent analysis of different machine learning techniques for dignosing five different diseases viz. Diabetes, heart disease, dengue, hepatitis and liver disease. They also highlighted the merits and de-merits of machine learning techniques used in diagnosisng thes e diseases. Sharma et al. [6] have critically examined the role and performance of different data mining techniques used in different lifestyle based human disorders. Authors extensively surveyed more than eighty manuscripts. Authors concluded that a lot of mining work has been carried out for diabetes and cardio problems. However, as a little attention has been paid to develop a predictive model for the diseases viz. ophthalmology, dentistry, and digestive disorders. Therefore, there is a need to explore or mine these areas.

\section{Review Methodology}

In this study, a systematic review methodology has been adopted. Different articles related to machine learning and their use in agriculture, finance, healthcare, education, and engineering has been explored by executing different queries on Google Scholar. The study covers more than a hundered articles. The articles embodied in this study have been extracted from peculiar indexing journals such as, IEEE, Elsevier, Springer, Plos|one etc The results found by executing the queries have been scrutinized and filtered based upon title and abstract. Additionally, the final decision regarding inclusion/exclusion has been made based upon the complete contents of the manuscripts. While exploring articles some of the restrictions were applied:

The language was restricted to English only.

- Only conference and journal articles were considered.
- Patents and other secondary sources have been ignored

\section{Review Results}

This section will highlight the role of supervised and nature-inspired computing(NIC) techniques in agriculture, finance, healthcare, education, engineering etc.

\subsection{Supervised Learning and Nature Inspired Computing Techniques}

Supervised learning techniques are important machine learning techniques that assist in data classification. Inspite of classification supervised learning techniques are also employed in programming or prediction problems. Stock forecasting, crop prediction, disease diagnosis, gene classification are some of the important applications of these techniques. Number of techniques such as Naive Bayes, Decision Tree, SVM, CART(Classification and Regression Tree) and regression have been designed and deployed for the same[1].

Nature Inspired Computing (NIC)Techniques are stochastic techniques which have been inspired from individual or swarm behaviour of various human beings, animals, birds and other natural phenonmenon like wind, water as well as universe.There are several NIC techniques. Some of most admired are GA(Genetic algorithm), ABC(Artificial Bee Colony),ALO(Ant Lion Optimization), FFA(Firefly Algorithm),GWO(Grey Wolf Optimization), Whale Optimization, Harmony Search and PSO(Particle Swarm Optimization). Inspite of long list and variation, these techniques have been significantly used to solve different computer science problems such as query optimization[23][24][25], image processing[26][27][28], network security[29][30], TSP (Travelling Salesman Problem)[31][32], task allocation[33] etc.

\subsection{Role of Machine Learning in Agriculture}

Machine learning has become a vital approach in the field of agriculture satisfying a number of objectives. These techniques have drastically changed the traditional way of performing agricultural activities. In last few years, it has been observed that a variety of supervised and NIC techniques have been used in predicting the wheat yield, weed detection, boosting crop yield, soil management, crop disease detection etc. ML techniques are also playing a vital role in yield prediction which is considered as the most important objective of agricultural planning. ML approach has been also used in modeling the river suspended sediment which is an important concern in managing the water resources[34]. Moreover, the ML techniques are extensively used in analyzing the agricultural data diagnosing crop diseases. In recent years, ML approaches have been employed for estimating 
the fruit ripeness. Nashwa El-Bendary et al.[35] have proposed a system for evaluating the tomato ripeness and the hybridization of SVM and LDA(Linear Discrimimant Analysis) is used to classify distinct stages of ripeness for tomatoes. They found that results produced using this hybrid approach are more useful than other classification techniques. Ulrich Weiss et al[36] have employed 3D LIDAR Sensor and supervised machine learning techniques for classifying plant species. Authors have used six plant species in their study and observed that SVM, Neural networks and Logistic regression are the best methods for classifying the plant species. Avat Shekoofa et al.[37] have worked on different screening, clustering, and decision tree models and concluded that CART is the best method for predicting maize grain yield. Farzaneh Sajedi-Hosseini et al.[38] stated that machine learning techniques have been also applied fruitfully in risk and hazards prediction in environmental sciences. Authors have used Boosted Regression Trees (BRT), Multivariate discriminant analysis (MDA), and Support Vector Machine (SVM) and Ensemble Modeling for assessing the probability of occurrence of pollution in groundwater and concluded that ensemble modeling gives better results than others. Authors suggested that the quality of groundwater can be improved by making the minimal use of nitrogenous fertilizers during irrigation .X.E.Pantazi et al.[39] have used three Self Organizing Map models viz. Counter-propagation Artificial Neural Network (CPANN), Supervised Kohonen Network (SKN) and XY-fusion network(XYF) for predicting wheat yield in a 22 ha field in Bedfordshire, UK and concluded that SKN model outperforms others with an accuracy of 91.3\%. A. Belayneh et al.[40] have employed the hybrid approach of Machine learning techniques such as ANN and SVR(Support Vector Regression) with wavelet analysis and ensemble techniques viz. Bootstrap and boosting techniques for the drought prediction and concluded that wavelet ensemble models perform better than the non-ensembled techniques.

\subsection{Role of Machine Learning in Finance}

Finance is another important research area for machine learning experts and data scientists. Stock and risk analysis are two major subareas of finance. In the business world, the stock market greatly affects the economic advancement of a country. A country's economic growth is directly proportional to the performance of the stock market. Stock markets generate ample amount of data so different machine learning methods are used for finding the hidden patterns from the data and predicting the stock prices, future trends which helps the investors to make investments in stock market. In spite of stock and risk analysis, loan approval, bankruptcy are other important research areas. Business enterprise is full of risks viz.market risk, credit risk and operation risk etc. so banks have to implement different policies to handle these risks. Machine learning techniques seem to be very useful for risk management[41]. Several research articles have been published in these areas using different machine learning techniques. Some of the major research works are pointed out below:

In 2012, Chopde et al.[42] used different data mining techniques for credit risk analysis. Different classifiers were used and based upon the predictive rate, the author concluded that the results obtained using decision tree outperformed other classifiers. Lee MC et al.[43] have used SVM (Support Vector Machine) and BPN(Back Propagation Neural Network) for analyzing the financial distress. They found that SVM is more useful than BPN in analyzing financial distress. Byanjankar A et al.[44] have used ANNs(Artificial Neural Networks) which helps the lenders in selecting better loan applications and making the predictions about credit risk.

T. Vafeiadis et al.[45] have applied five major classification techniques of machine learning viz. BPN(Back Propagation Network), SVM, DT(Decision Tree), NB(Naïve Bayes) and LR(Logistic Regression) for making the churn prediction of customers of a telecommunication company. Authors compared the classification methods with their boosted versions and concluded that SVM-POLY(Polynomial Kernel) gives better results in terms of accuracy and F-measure. Junichiro Mori et al.[46] have employed SVM for identifying relationships between new customers and suppliers in a business firm and reciprocal relationships among them. Authors stated that SVM shows the significant performance in predicting customer-supplier relationships by providing better F-measure and reciprocity values.

Shubham Jain et al.[47] used three machine learning techniques viz. LR(Linear Regression), RF(Random Forest) and MLP(Multilayer Perceptron) for analyzing the trend of stock market indices viz.NYTimes and DOW Jones Industrial Average. Authors stated that MLP outperforms the other two techniques in predicting the stock values. Osman Hegazy et al.[48] have proposed a hybrid approach of PSO(Particle Swarm Optimization) and LS-SVM(Least Square Support Vector Machine) for predicting the stock market price. Authors have used thirteen different financial technical indicators in their study and compared the proposed approach(PSO-LSSVM) with LS-SVM and ANN-BP( Artificial Neural Network-Back Propagation Neural Network) and concluded that proposed hybrid approach outperforms other approaches. Nanxi Wang[49] has used different machine learning techniques viz. SVM, NN with dropout, Autoencoder for bankruptcy prediction. Author has compared these three techniques with the traditional methods viz. GA(Genetic Algorithm), Inductive Learning and Logistic Regression and observed that SVM, NN with dropout and Autoencoder gives better accuracies than the older methods. Mustansar Ali Ghazanfar et al.[50] have employed distinct machine learning techniques for predicting the Karachi Stock Exchange 
(KSE) and concluded that Ada- Boost, MLP and Bayesian Network give better outcomes than others.

Ashish Sharma et al.[18] have surveyed different regression techniques viz. Polynomial regression, RBF(Radial Basis Function) regression, Sigmoid regression and Linear regression and concluded that Linear Regression is considered as a better one in making the predictions than others. Regression analysis is basically used in finding the cause and effect relationships between dependent and independent variables. Yuqinq $\mathrm{He}$ et al.[51] have calculated the twelve technical indicators for analyzing the stock market trend. Authors have also studied the three different feature selection algorithms viz. Principle Component Analysis (PCA), Genetic Algorithm (GA) and Sequential Forward Selection(SFS) along with their merits and de-merits.

\subsection{Role of Machine Learning in Education}

Machine Learning(ML) techniques hold a great obligation for education. These techniques have been employed in the prediction of student dropout in higher education. [52]. ML techniques are also applicable in performing the student modeling. Dursun Delen[9] has used SVM decision trees, neural networks, and logistic regression and ensemble methods and observed that ensemble methods perform better than others for predicting the student's retention management. S. Kotsiantis et al.[53] have employed ensemble classifiers for the prediction of student 's performance in distance education which allows the teachers to understand the fact that which students will complete their course of study and which will not. Getting placed in a renowned company is a dream of every student and they work hard to achieve their goal. Every reputed organization has a placement cell for selecting the potential students and improving their skills. ML techniques have been also employed in this domain. Sentkil Kumar Thangave et al.[54] have presented a recommendation system for the student's placement analysis an achieved an accuracy of $71.66 \%$. Authors have used five different data mining techniques viz. Naïve Bayes, MLP, Reptree, J48, decision tree etc. for predicting the academic performance of students. A.Pavithra et al.[55] have proposed a framework based on five different machine learning techniques viz. Decision tree, Naive Bayes, J48, predicting the academic performance of students. Authors have also mentioned the various socio-economic, non-educational factors that affect the academic conduct of students viz. semester percentage annual income of student, higher secondary marks, the occupation of father, locality of students, psychology etc. Pena-Ayala et al.[56] have presented an extensive survey of various data mining techniques used for the student modeling. Authors have also discussed computer-based education systems as an substitute to the traditional education systems. Various flaws and strengths of educational data mining are also mentioned.

\subsection{Role of Machine Learning in Engineering}

In the last few years, it has been noticed that machine learning is providing viable alternatives to the traditional methods of solving the engineering problems in different domains such as software engineering, civil engineering, chemical engineering, mechanical engineering, computer engineering etc. Jagath Sri Lal Senanayaka et al.[57] have used SVM for the detection and classification of bearing faults at an early stage. Authors stated that bearings are the most important component of machinery used in the industry and in household devices therefore, early detection of faults in bearings is very crucial. Carbon dioxide $\left(\mathrm{CO}_{2}\right)$ is known as one of the major Green House Gases. Examining the virtue of $\mathrm{CO}_{2}$ requires large number of resources as well as time, therefore, Zhien Zhanga et al.[58] have used ML techniques viz.back-propagation neural network (BPNN) and general regression neural network (GRNN) for rapid prediction of thermodynamic properties of $\mathrm{CO}_{2}$ in solution environment, its solubility, viscosity, density in potassium lysinate solution amalgamated solution with monoethanolamine (MEA). Authors concluded that ML techniques provide high speed and meticulous prediction of thermodynamic properties of $\mathrm{CO}_{2}$. Edward W. Lowe et al.[59] have used three different ML techniques viz. ANN, SVM, and K$\mathrm{NN}$ for the prediction of $\log \mathrm{P}$ which is a partition coefficient which is a measure of hydrophilicity of a compound and concluded that ML approaches give better prediction than $\mathrm{X} \log \mathrm{P}$ which is also a well-established method of predicting $\log$ P. Ruchika Malhotra et al.[60] have proposed different models for the enhancement of software quality. In their study authors have used six different machine learning techniques viz. Adaboost, Random Forest, MLP, Bagging, Genetic Programming and SVM and one statistical method for determining the faulty classes in the software development. Authors have evaluated nineteen different metrics and concluded that the models based on bagging and random forest methods outperformed all the other models. Adriano L.I. Oliveira et al.[61] have proposed a hybrid approach based on GA and machine learning techniques for estimating the software efforts. In this study authors have used three different machine learning techniques viz.MLP, SVR(Support Vector Regression) and Decision Tree(M5P) and stated that proposed approach gives better results in terms of accuracy.

\subsection{Role of Machine Learning in Healthcare}

Nowadays, a large number of people are suffering from different human disorders such as diabetes, cancer, cardio, neuro digestive, and psychological disorders. A huge amount of data related to medical diagnosis is available, so it is required to classify the whole data to make predictions about the diseases and 
their treatments. Machine learning techniques can be used in diagnosing different diseases viz. breast cancer, heart problems, skin problems, Alzheimer's disease, diabetes etc. [62].

Several authors have employed differently supervised and NIC(Nature Inspired Computing) techniques for early diagnosis of these human disorders. Some of the studies are briefly presented below:

Tarigoppula V.S. Sriram et al.[63] have employed different machine learning techniques viz. Naïve Bayes, Logistic Regression, KStar, ADTree, J48, SVM, Random Forest etc. for diagnosing Parkinson disease. They have compared the machine learning techniques used in their study and concluded that Random Forest outperforms others in terms of accuracy. Deepa Gupta et al.[64] have applied machine learning techniques for diagnosing the eleven different chronic diseases viz. Diabetes, Cancer, Chronic heart failure, Ischemic heart disease, Chronic kidney disease, Alzheimer, Obsessive pulmonary disorder, Osteoporosis, Depression, Arthritis and Stroke and generated the diagnostic codes. They have employed Adaboost and Information Gain on the CMS(Centre for Medicare Services) dataset and concluded that AdaBoost outperforms. Mehrbakhsh Nilashi et al.[65] have proposed a knowledge-based system for diagnosing the real world datasets by using different prediction techniques, noise removal, and clustering techniques. Authors observed that a hybrid approach of fuzzy rule-based techniques, clustering techniques and PCA(Principal Component Analysis) give better results in terms of disease prediction accuracy. Shashikant Ghumbre et al.[66] have performed the diagnosis of heart disease using SVM and Radial Basis Function(RBF) network. Authors have conducted a statistical analysis of patients datasets in terms of accuracy, sensitivity, and specificity and observed that SVM gives better results than RBF in terms of the parameters used. Javad Salimi Sartakhti et al.[67] have proposed a hybrid approach of SVM and Simulated Annealing(SA) for diagnosing hepatitis disease. The proposed approach is compared with other classification techniques mentioned in the literature in terms of accuracy, recall, and F-measure and it is concluded that the proposed method outperforms the other methods.

\section{Summary of Review Results}

Table1 depicts the accuracies of different machine learning techniques used in particular applications. It is found that, in general twelve different supervised learning techniques such as SVM, Naive Bayes, Decision Tree/C4.5, Logistic Regression, MLP, Neural Networks, ANN, CART, AdaBoost, AutoEncoders, SKN(Supervised Kohonen Networks), Ensemble Modeling have employed to solve different problems of agriculture, finance, healthcare, education and engineering. The rate of prediction is different using different supervised learning techniques. All these details are highlighted in Table1.

Table2 summarized the results of the use of eleven different nature-inspired computing techniques viz. Genetic Algorithm, Grey Wolf Optimization, Crow Search Algorithm, Ant Lion Optimization, Firefly algorithm, Ant Colony Optimization, Whale Optimization, Artificial Bee Colony, Cuckoo Search, Multiverse Optimization(MVO) and Hybrid approach in five major research domains such as agriculture, finance, healthcare, education and engineering. It is observed that as compared to supervised learning techniques better predictive results have been achieved using different NIC techniques.

\subsection{Publication Trend}

Figure 2 depicts the general publication trend of last ten years of applications of machine learning in the five major research areas viz. agriculture, finance, healthcare, education, and engineering within a period of 2010 up 2019. It has been observed from the table that a large number of articles have been published in the field of engineering using machine learning techniques during this period.
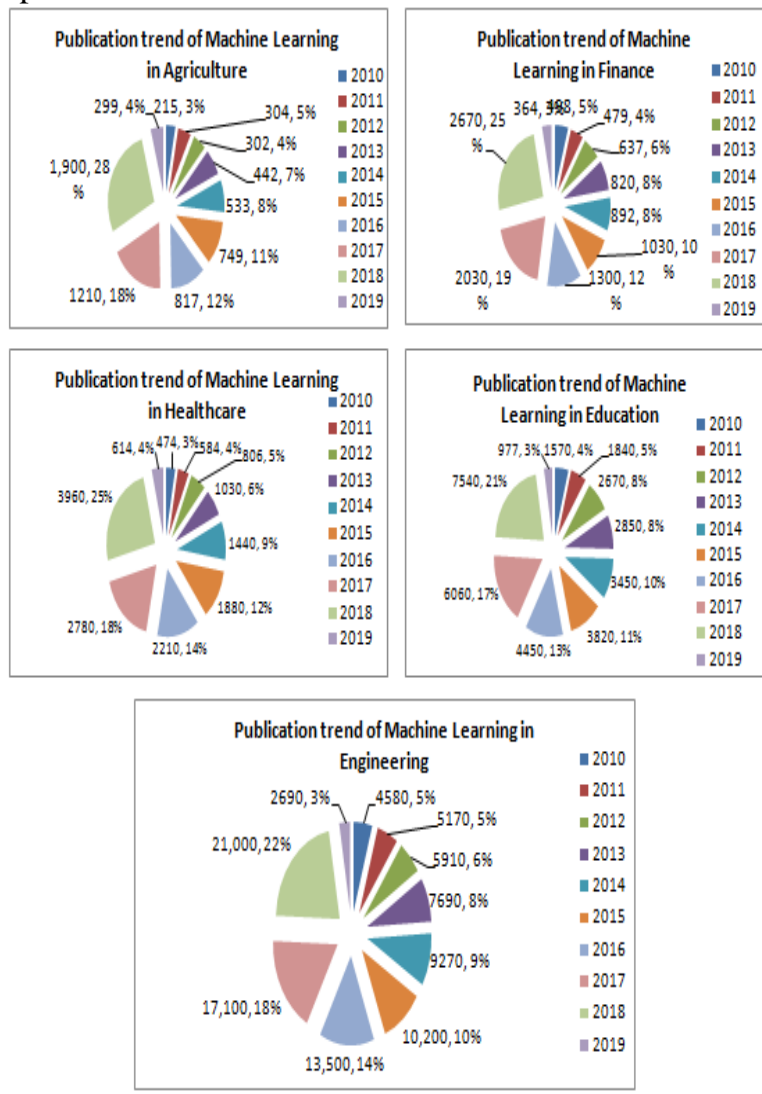

Figure 2: Publication Trend 
Table 1: Summary of Supervised Learning (Traditional) Techniques

\begin{tabular}{|c|c|c|c|c|c|c|c|c|c|c|c|c|c|c|}
\hline Author, Year & $\sum_{\infty}^{\infty}$ & 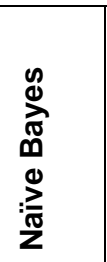 & 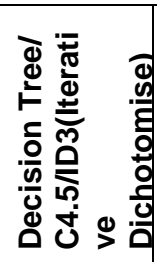 & 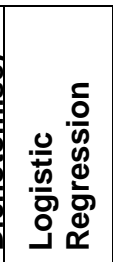 & $\stackrel{n}{\Sigma}$ & 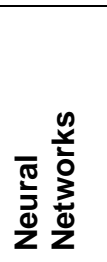 & $\frac{z}{z}$ & 辇 & $\begin{array}{l}\bar{D} \\
8 \\
0 \\
0 \\
\frac{\pi}{0}\end{array}$ & 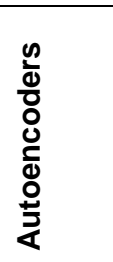 & z & 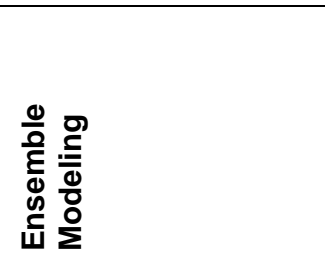 & $\begin{array}{l}\frac{5}{\frac{0}{7}} \\
\frac{.0}{0} \\
\frac{0}{0} \\
\frac{0}{4}\end{array}$ & 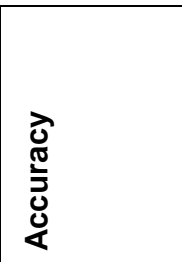 \\
\hline $\begin{array}{l}\text { Farzaneh Sajedi- } \\
\text { Hosseini(2018)[3 } \\
\text { 8] }\end{array}$ & & & & & & & & & & & & $\checkmark$ & $\begin{array}{l}\text { Risk Assessment } \\
\text { of nitrate } \\
\text { groundwater } \\
\text { contamination }\end{array}$ & Above $80 \%$ \\
\hline $\begin{array}{l}\text { Shubham Jain et } \\
\text { al.,(2018)[47] }\end{array}$ & & & & & $\checkmark$ & & & & & & & & Stock Analysis & $\begin{array}{l}\text { Not } \\
\text { mentioned }\end{array}$ \\
\hline $\begin{array}{l}\text { Jagath Sri Lal } \\
\text { Senanayaka et } \\
\text { al.,(2017)[57] }\end{array}$ & $\checkmark$ & & & & & & & & & & & & $\begin{array}{l}\text { Bearing Fault } \\
\text { Classification }\end{array}$ & $96 \%$ \\
\hline $\begin{array}{l}\text { Mustansar Ali } \\
\text { Ghazanfar, et } \\
\text { al.,(2017)[50] }\end{array}$ & & & & & & & & & $\checkmark$ & & & & $\begin{array}{l}\text { Prediction of Stock } \\
\text { Exchange Index }\end{array}$ & $\begin{array}{l}\text { Not } \\
\text { mentioned }\end{array}$ \\
\hline $\begin{array}{l}\text { Nanxi Wang } \\
(2017)[49]\end{array}$ & $\checkmark$ & & & & & $\checkmark$ & & & & $\checkmark$ & & & $\begin{array}{l}\text { Bankruptcy } \\
\text { Prediction }\end{array}$ & $\begin{array}{l}\text { Not } \\
\text { mentioned }\end{array}$ \\
\hline $\begin{array}{l}\text { Sentkil Kumar } \\
\text { Thangavel et } \\
\text { al.,(2017)[54] }\end{array}$ & & & & & & & & & & & & $\begin{array}{l}\text { Logistic } \\
\text { regression+Decision } \\
\text { tree+Naïve Bayes+ } \\
\text { Metabagging } \\
\text { classifier+Classificati } \\
\text { on via Regression }\end{array}$ & $\begin{array}{l}\text { Student } \\
\text { Placement } \\
\text { Analyzer }\end{array}$ & $84.42 \%$ \\
\hline $\begin{array}{l}\text { Lovenoor Aulck } \\
\text { et al,.(2016)[52] }\end{array}$ & & & & $\sqrt{ }$ & & & & & & & & & Student Dropout & $66.59 \%$ \\
\hline $\begin{array}{l}\text { X.E. Pantazi et } \\
\text { al.,(2016)[39] }\end{array}$ & & & & & & & & & & & $\checkmark$ & & Wheat yield & $91 \%$ \\
\hline $\begin{array}{l}\text { T. Vafeiadis et } \\
\text { al.,(2015)[45] }\end{array}$ & $\checkmark$ & & & & & & & & & & & & Customer Churn & $97 \%$ \\
\hline $\begin{array}{l}\text { T. K. Das } \\
(2015)[68]\end{array}$ & & $\sqrt{ }$ & & & & & & & & & & & $\begin{array}{l}\text { Customer } \\
\text { Classification }\end{array}$ & $95 \%$ \\
\hline $\begin{array}{l}\text { Jigar Patel et } \\
\text { al.,(2014)[69] }\end{array}$ & & $\sqrt{ }$ & & & & & & & & & & & Stock Analysis & $90.19 \%$ \\
\hline $\begin{array}{l}\text { Nashwa El- } \\
\text { Bendary }(2014)[3 \\
\text { 5] }\end{array}$ & & & & & & & & & & & & $\begin{array}{l}\text { SVM+PCA+LDA(Line } \\
\text { ar discriminant } \\
\text { analysis) }\end{array}$ & Tomato ripeness & $90.2 \%$ \\
\hline $\begin{array}{l}\text { Avat Shekoofa et } \\
\text { al.,(2014)[37] }\end{array}$ & & & & & & & & $\checkmark$ & & & & & Maize Grain yield & $\begin{array}{l}\text { Not } \\
\text { mentioned }\end{array}$ \\
\hline
\end{tabular}




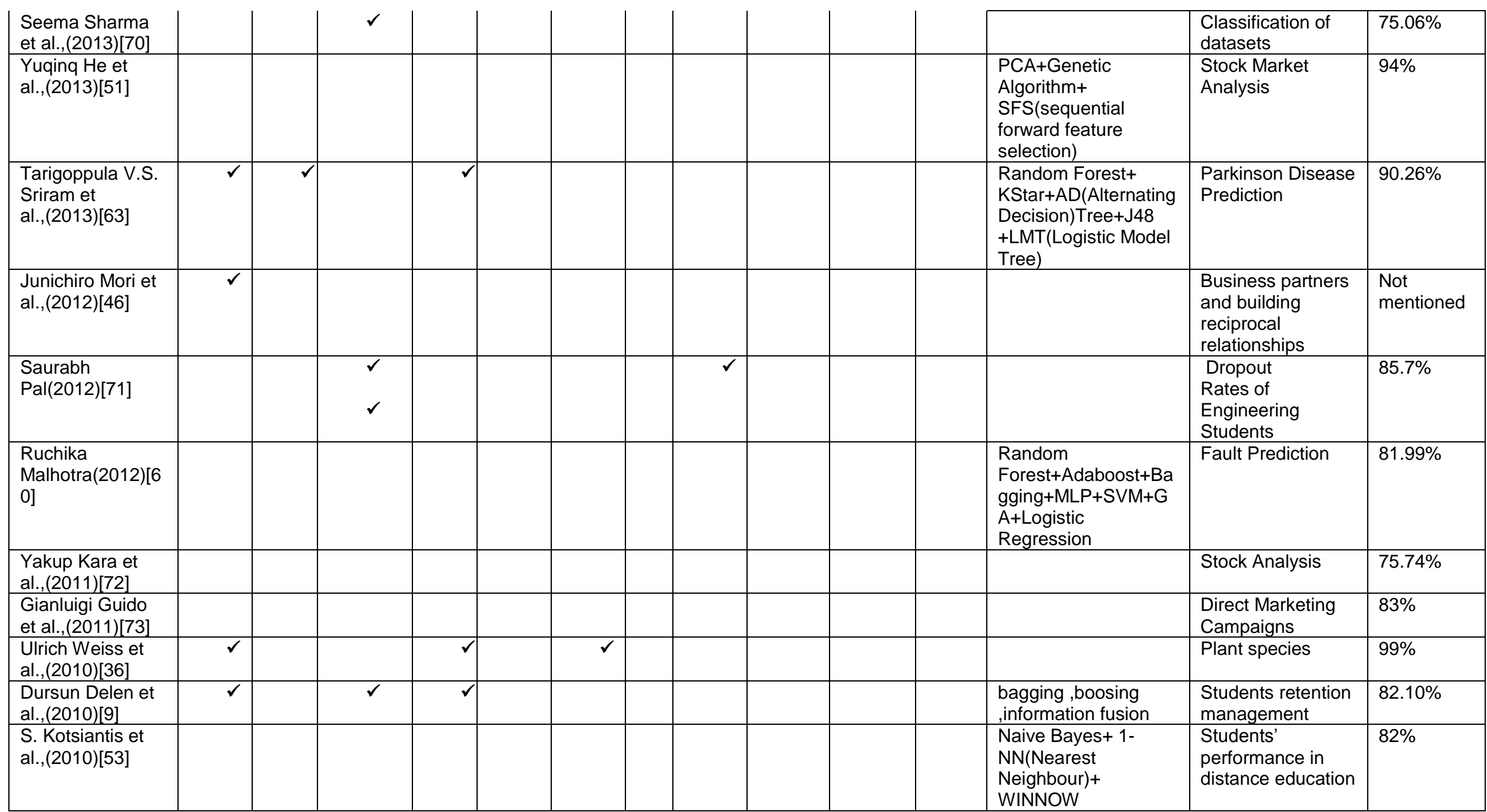

Table 2: Summary of Nature-Inspired Computing Techniques 
Role and Performance of Different Traditional Classification and Nature-Inspired Computing Techniques in Major Research Areas

\begin{tabular}{|c|c|c|c|c|c|c|c|c|c|c|c|c|c|}
\hline 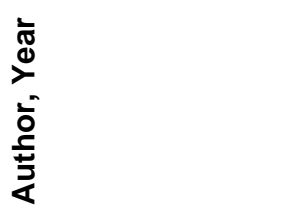 & ৫্ড & $\sum_{0}^{\circ}$ & હુ & 온 & $\underset{4}{\mathbb{4}}$ & O & 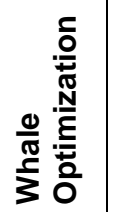 & 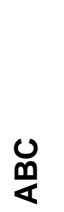 & 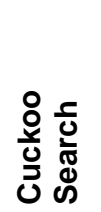 & 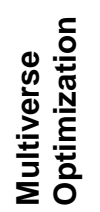 & 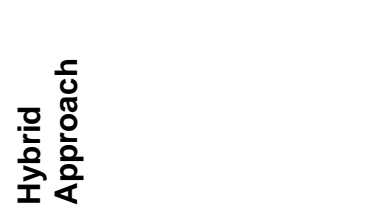 & $\begin{array}{l}\frac{.}{0} \\
\frac{10}{\pi} \\
\frac{0}{0} \\
\frac{0}{2}\end{array}$ & 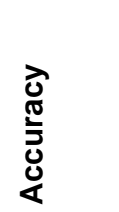 \\
\hline $\begin{array}{l}\text { N. Emam et } \\
\text { al.,(2019)[74] }\end{array}$ & & & & & & & & & & & $\begin{array}{l}\text { Affinity } \\
\text { Propagation+FFA+SVM }\end{array}$ & Breast Cancer & $98.60 \%$ \\
\hline $\begin{array}{l}\text { G. Ignisha } \\
\text { Rajathi(2019)[75] }\end{array}$ & & & & & & & & & & & $\begin{array}{l}\text { Whale Optimization with } \\
\text { Simulated Annealing } \\
\text { +Ensemble Classifier }\end{array}$ & Liver Disease & $98 \%$ \\
\hline $\begin{array}{l}\text { M. Prabukumar et } \\
\text { al.,(2019)[76] }\end{array}$ & & & & & & & & & & & $\begin{array}{l}\text { Cuckoo Search Algorithm } \\
+ \text { +SVM }\end{array}$ & Lung Cancer & $98.51 \%$ \\
\hline $\begin{array}{l}\text { PrernaSharma et } \\
\text { al.,(2018)[77] }\end{array}$ & & $\checkmark$ & & & & & & & & & & Parkinson's disease & $94.83 \%$ \\
\hline $\begin{array}{l}\text { llyas } \\
\text { Benmessahel et } \\
\text { al.,(2018)[78] }\end{array}$ & & & & & & & & & & & $\mathrm{MVO}+\mathrm{ANN}$ & $\begin{array}{l}\text { Intrusion Detection } \\
\text { System }\end{array}$ & $99.61 \%$ \\
\hline $\begin{array}{l}\text { Ramit Sawhney et } \\
\text { al.,(2018)[79] }\end{array}$ & & & & & & & & & & & $\begin{array}{l}\text { Binary FFA+ Random } \\
\text { Forest(RF) }\end{array}$ & Cancer & $97.69 \%$ \\
\hline $\begin{array}{l}\text { Prerna Sharma et } \\
\text { al. (2018)[80] }\end{array}$ & & & & & & & & & & & Improved GWO+ ANN & Protein Structure & $91 \%$ \\
\hline $\begin{array}{l}\text { HuiWang et } \\
\text { al.,(2018)[81] }\end{array}$ & & & & & $\checkmark$ & & & & & & & $\begin{array}{l}\text { Demand estimation } \\
\text { of water resources }\end{array}$ & $97.91 \%$ \\
\hline $\begin{array}{l}\text { R.S. Chithra et } \\
\text { al.,(2018)[82] }\end{array}$ & & & $\checkmark$ & & & & & & & & & Tuberculosis & $96.15 \%$ \\
\hline $\begin{array}{l}\text { Deepak Gupta et } \\
\text { al.,(2018)[83] }\end{array}$ & & & $\checkmark$ & & & & & & & & & Parkinson's disease & $100 \%$ \\
\hline $\begin{array}{l}\text { Gehad Ismail } \\
\text { Sayed et } \\
\text { al.,(2017)[84] }\end{array}$ & & & $\checkmark$ & & & & & & & & & Feature Selection & $100 \%$ \\
\hline $\begin{array}{l}\text { ZeinabArabasadi } \\
\text { et al.,(2017)[85] }\end{array}$ & & & & & & & & & & & $\begin{array}{l}\text { GA +Neural } \\
\text { Networks }\end{array}$ & Heart disease & $93.85 \%$ \\
\hline $\begin{array}{l}\text { Abdalla Mostafa et } \\
\text { al.,(2016)[86] }\end{array}$ & & & & $\checkmark$ & & & & & & & & MRI Liver & $94.49 \%$ \\
\hline $\begin{array}{l}\text { Hoda Zamani et } \\
\text { al.,(2016)[87] }\end{array}$ & & & & & & & $\checkmark$ & & & & & Diseases Diagnosis & $97.86 \%$ \\
\hline
\end{tabular}


Samriti Sharma, G. Singh, D. Singh

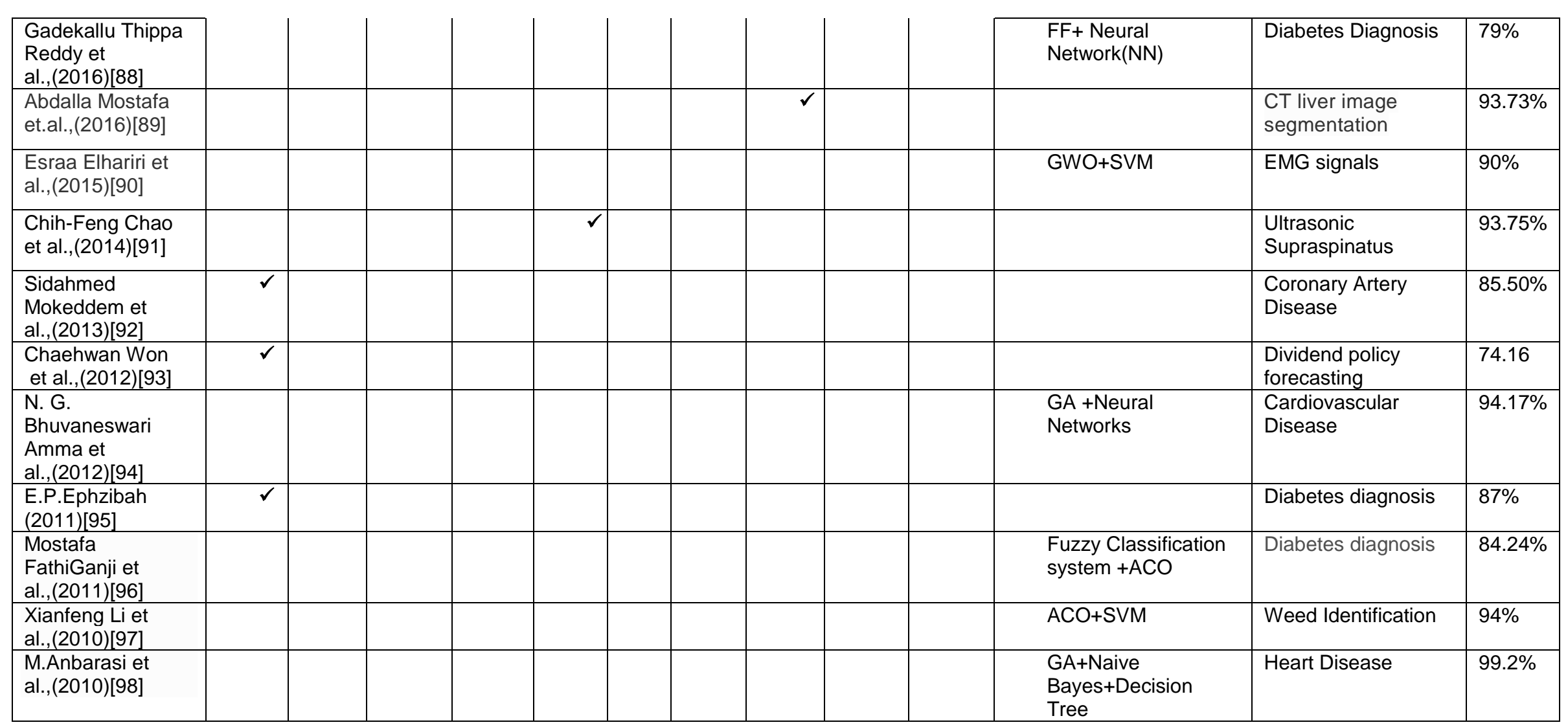


Table 3: Role of NIC Techniques

\begin{tabular}{|c|c|c|c|c|c|}
\hline Algorithms/Domains & Agriculture & Finance & Healthcare & Education & Engineering \\
\hline Genetic Algorithm(GA) & 17,000 & 16,800 & 16,200 & 31,400 & 298,000 \\
\hline $\begin{array}{c}\text { Grey Wolf } \\
\text { Optimization(GWO) }\end{array}$ & 93 & 80 & 52 & 255 & 1500 \\
\hline $\begin{array}{c}\text { Crow Search } \\
\text { Algorithm(CSA) }\end{array}$ & 30 & 19 & 29 & 62 & 396 \\
\hline Ant Lion Optimization(ALO) & 21 & 16 & 19 & 65 & 395 \\
\hline Fire Fly Algorithm(ALO) & 785 & 848 & 505 & 2720 & 13,700 \\
\hline $\begin{array}{c}\text { Ant Colony } \\
\text { Optimization(ACO) }\end{array}$ & 4080 & 4250 & 2890 & 15,400 & 41,100 \\
\hline Whale Optimization & 61 & 70 & 63 & 203 & 1140 \\
\hline Artificial Bee Colony(ABC) & 1560 & 1700 & 1080 & 7040 & 18,100 \\
\hline Monkey Search & 25 & 23 & 12 & 72 & 301 \\
\hline Cuckoo Search & 726 & 714 & 634 & 2850 & 13,400 \\
\hline $\begin{array}{c}\text { Multiverse } \\
\text { Optimization(MVO) }\end{array}$ & 0 & 1 & 0 & 3 & 19 \\
\hline
\end{tabular}

Table 3 depicts the publication trend of different nature-inspired algorithms in five research areas viz. agriculture, finance, healthcare, education, engineering. It has been observed that ample amount of work has been published in these domains using Genetic Algorithms(GA), Ant Colony Optimization(ACO) and Artificial Bee Colony(ABC) algorithm and a relatively lesser number of articles have been published using other algorithms. Additionally, little attention has been paid to use of multiverse optimization in five major domains(agriculture, finance, healthcare, education, engineering).

Table 4 : Details of Publications

\begin{tabular}{|l|l|l|l|}
\hline \multicolumn{1}{|c|}{ Author Name } & \multicolumn{1}{c|}{ Citation } & \multicolumn{1}{c|}{ Journal } & Country \\
\hline $\begin{array}{l}\text { Andrea Mannini, And Angelo Maria } \\
\text { Sabatini(2010)[99] }\end{array}$ & 538 & Sensors & Italy \\
\hline $\begin{array}{l}\text { Christos A. Frantzidis et } \\
\text { al.,(2010)[100] }\end{array}$ & 131 & IEEE Xplore & Kreece \\
\hline Youn-Jung Son, et al.,(2010)[101] & 55 & KoreaMed Synapse \\
\hline Asha Rajkumar et al.,(2010)[102 & 136 & $\begin{array}{l}\text { Global Journal of Computer Science } \\
\text { and Technology }\end{array}$ & India \\
\hline Ulrich Weiss et al.,(2010)[36] & 34 & $\begin{array}{l}\text { Ninth International Conference on } \\
\text { Machine Learning and Applications }\end{array}$ & Germany \\
\hline Edward W. Lowe et al.,(2011)[59] & 5 & IEEE Xplore & USA \\
\hline Ketaki Chopde et al.,(2012)[42] & 1 & $\begin{array}{l}\text { International Journal of Engineering } \\
\text { and Advanced Technology }\end{array}$ & India \\
\hline Wei-Yang Lin, et al.,(2012)[17] & 120 & IEEE Transactions on Systems & Taiwan \\
\hline & 255 & International Journal of Bio-Science & India \\
\hline
\end{tabular}
authors, universities and the journals in publishing the different articles related to the role and performance of machine learning in five different research domains viz. agriculture, finance, healthcare, education, and engineering. 


\begin{tabular}{|c|c|c|c|}
\hline Divya Tomar et al.,(2013)[7] & & and Bio-Technology & \\
\hline Yun Hwan Kim et al.,(2014)[13] & 5 & $\begin{array}{l}2013 \text { International Conference on } \\
\text { Future Software Engineering and } \\
\text { Multimedia Engineering }\end{array}$ & Korea \\
\hline Avat Shekoofa et al.,(2014)[37] & 24 & Plos|One & $\begin{array}{l}\text { USA, } \\
\text { Iran,Australia }\end{array}$ \\
\hline Vanaja et al.,(2015)[62] & 13 & Journal of Computer Science & India \\
\hline Shubham Bind et al.,(2015)[20] & 14 & $\begin{array}{lcc}\text { International } & \text { Journal of Computer } \\
\text { Science } & \text { and } & \text { Information } \\
\text { Technologies } & & \end{array}$ & India \\
\hline Shweta H. Jambukia et al.,(2015)[22] & 35 & $\begin{array}{l}\text { International Conference on } \\
\text { Advances in Computer Engineering } \\
\text { and Applications }\end{array}$ & India \\
\hline Vivek Rajput et al.,(2016)[16] & 3 & $\begin{array}{l}\text { International Journal of Computer } \\
\text { Science and Mobile Computing }\end{array}$ & India \\
\hline Subhadra Mishra et al.,(2016)[14] & 10 & $\begin{array}{l}\text { Indian Journal of Science and } \\
\text { Technology }\end{array}$ & India \\
\hline Ernest Mwebaze et al.,(2016)[103] & 10 & IEEE Xplore & Uganda \\
\hline M. Sharma et al.,(2017)[6] & 6 & Elsevier Masson & India \\
\hline Wei-Chao Lin et al.,(2017)[5] & 4 & Emeraldinsight & Taiwan \\
\hline Zachary W. Ulissi et al.,(2017)[104] & 49 & ACS Catalysis & United States \\
\hline Hao Li et al.,(2017)[105] & 38 & International Journal of Photoenergy & USA and China \\
\hline $\begin{array}{l}\text { Jagath Sri Lal Senanayaka et } \\
\text { al.,(2017)[57] }\end{array}$ & 12 & IEEE Xplore & Norway \\
\hline Sentkil Kumar Thangavel(2017)[54] & 6 & IEEE Xplore & India \\
\hline Ashish Sharma et al.,(2017)[18] & 5 & $\begin{array}{lcr}\text { International } & \text { Conference } & \text { on } \\
\text { Electronics, Communication } & \text { and } \\
\text { Aerospace Technology } & \\
\end{array}$ & India \\
\hline $\begin{array}{l}\text { Konstantinos G. Liakos et } \\
\text { al.,(2018)[12] }\end{array}$ & 5 & Sensors & Greece \\
\hline M. Sharma et al.,(2018)[106] & 2 & $\begin{array}{l}\text { EAI Endorsed Transactions } \\
\text { on Scalable Information Systems }\end{array}$ & India \\
\hline Prableen Kaur et al.,(2018)[19] & 1 & $\begin{array}{llr}\text { International } & \text { Journal } & \text { of } \\
\text { Pharmaceutical } & \text { Sciences } & \text { and } \\
\text { Research } & & \\
\end{array}$ & India \\
\hline Prableen Kaur et al.,(2018)[21] & 3 & Proceedia Computer Science & India \\
\hline ZhienZhang et al.,(2018)[107] & 12 & Journal of $\mathrm{CO}_{2}$ Utilization & China \\
\hline Joeky T. Senders et al.,(2018)[108] & 12 & Springer & USA \\
\hline M.Sharma et al.,(2018)[109] & 4 & Data & India \\
\hline O. Nadjemia et al.,(2019)[110] & 26 & $\begin{array}{l}\text { Renewable and Sustainable Energy } \\
\text { Reviews }\end{array}$ & Algeria \\
\hline
\end{tabular}

The articles published in the five domains are further examined and the details are mentioned in the Table4. It has been observed from the table that a number of researchers have done their research in these domains and the contribution of the researchers and their universities are highlighted in the table. On the average the rate of citations is in two digits. However, some special cases of three digits are also present.

\section{Conclusion}

This paper presents the systematic review of role and performance of machine learning techniques in five major research areas viz. healthcare, education, finance, agriculture, and engineering. Some of the major applications areas of ML techniques are highlighted. The research works of some of the key authors related to the use of ML techniques particularly in agriculture, finance, education, engineering, and healthcare has been examined and presented in this study. Furthermore, to examine the rate of publication, the publication trend of the related articles has been analyzed. From the last ten year of publication trend, it is observed that a significant amount of research work has been carried out for exploring the role and performance of different ML techniques in engineering. However, agriculture, finance, and healthcare still need more attention. Additionally, as far as nature inspired computing (NIC) techniques are concerned, more attention is required for multiverse optimization techniques. Moreover, the latest and emerging NIC techniques should also be employed in these areas and their performance need to be examined. 


\section{References}

1. Saikat Dutt, Suramanian Chandramouli, Amit Kumar Das. "Machine Learning". First impression, Pearson.

2. Fatima, Meherwar, and Maruf Pasha. "Survey of machine learning algorithms for disease diagnostic." Journal of Intelligent Learning Systems and Applications 9.01 (2017): 1.

3. Buşoniu, Lucian, Robert Babuška, and Bart De Schutter. "Multi-agent reinforcement learning: An overview." Innovations in multi-agent systems and applications-1. Springer, Berlin, Heidelberg, 2010. 183-221.

4. Reich, Yoram, and S. V. Barai. "Evaluating machine learning models for engineering problems." Artificial Intelligence in Engineering 13.3 (1999): 257-272.

5. Lin, Wei-Chao, Shih-Wen Ke, and Chih-Fong Tsai. "Top 10 data mining techniques in business applications: a brief survey." Kybernetes 46.7 (2017): 1158-1170.

6. Sharma, M., G. Singh, and R. Singh. "Stark Assessment of Lifestyle Based Human Disorders Using Data Mining Based Learning Techniques." IRBM 38.6 (2017): 305-324.

7. Tomar, Divya, and Sonali Agarwal. "A survey on Data Mining approaches for Healthcare." International Journal of BioScience and Bio-Technology 5.5 (2013): 241266.

8. Sharma, Navin, et al. "Predicting solar generation from weather forecasts using machine learning." 2011 IEEE international conference on smart grid communications (SmartGridComm). IEEE, 2011.

9. Delen, Dursun. "A comparative analysis of machine learning techniques for student retention management." Decision Support Systems 49.4 (2010): 498-506.

10. Jahangiri, Arash, Hesham Rakha, and Thomas A. Dingus. Predicting red-light running violations at signalized intersections using machine learning techniques. No. 15-2910. 2015.

11. Kober, Jens, J. Andrew Bagnell, and Jan Peters. "Reinforcement learning in robotics: A survey." The International Journal of Robotics Research 32.11 (2013): 1238-1274.

12. Liakos, Konstantinos, et al. "Machine learning in agriculture: A review." Sensors 18.8 (2018): 2674.

13. Kim, Yun Hwan, et al. "Crop pests prediction method using regression and machine learning technology: Survey." IERI Procedia 6 (2014): 52-56.

14. Mishra, Subhadra, Debahuti Mishra, and Gour Hari Santra. "Applications of machine learning techniques in agricultural crop production: a review paper." Indian J. Sci. Technol 9.38 (2016): 1-14.

15. Cai, Fan, Nhien-An Le-Khac, and Tahar Kechadi. "Clustering approaches for financial data analysis: a survey." arXiv preprint arXiv:1609.08520 (2016).

16. Rajput, Vivek, and Sarika Bobde. "Stock market forecasting techniques: literature survey." Int J Comput Sci Mob Comput5.6 (2016): 500-506.

17. Lin, Wei-Yang, Ya-Han $\mathrm{Hu}$, and Chih-Fong Tsai. "Machine learning in financial crisis prediction: a survey." IEEE Transactions on Systems, Man, and Cybernetics, Part C (Applications and Reviews) 42.4 (2012): 421436.

18. Sharma, Ashish, Dinesh Bhuriya, and Upendra Singh. "Survey of stock market prediction using machine learning approach." 2017 International conference of Electronics, Communication and Aerospace Technology (ICECA). Vol. 2. IEEE, 2017.

19. Kaur, Prableen, and Manik Sharma. "Analysis of Data Mining and Soft Computing Techniques in Prospecting Diabetes Disorder in Human Beings: A Review." Int. J. Pharm. Sci. Res 9 (2018): 2700-2719.

20. Bind, Shubham, et al. "A survey of machine learning based approaches for Parkinson disease prediction." International Journal of Computer Science and Information Technologies6.2 (2015): 1648-1655.

21. Kaur, Prableen, Manik Sharma, and Mamta Mittal. "Big Data and Machine Learning Based Secure Healthcare Framework." Procedia computer science 132 (2018): 1049-1059.

22. Jambukia, Shweta H., Vipul K. Dabhi, and Harshadkumar B. Prajapati. "Classification of ECG signals using machine learning techniques: A survey." 2015 International Conference on Advances in Computer Engineering and Applications. IEEE, 2015.

23. Sharma, Manik, et al. "Stochastic Analysis of DSS Queries for a Distributed Database Design." International Journal of Computer Applications 83.5 (2013).

24. Sharma, M., G. Singh, and R. Singh. "Clinical decision support system query optimizer using hybrid Firefly and controlled Genetic Algorithm." Journal of King Saud UniversityComputer and Information Sciences (2018).

25. Sharma, Manik, and Gurdev Singh. "Analysis of Joins and Semi-joins in Centralized and Distributed Database Queries." 2012 International Conference on Computing Sciences. IEEE, 2012.

26. Singh, Vijai, and A. K. Misra. "Detection of unhealthy region of plant leaves using image processing and genetic algorithm." 2015 International Conference on Advances in 
Computer Engineering and Applications. IEEE, 2015.

27. Hashemi, Sara, et al. "An image contrast enhancement method based on genetic algorithm." Pattern Recognition Letters 31.13 (2010): 1816-1824

28. Draa, Amer, and Amira Bouaziz. "An artificial bee colony algorithm for image contrast enhancement." Swarm and Evolutionary computation 16 (2014): 69-84.

29. Kshirsagar, Vivek K., Sonali M. Tidke, and Swati Vishnu. "Intrusion detection system using genetic algorithm and data mining: An overview." International Journal of Computer Science and Informatics ISSN (PRINT) 2231 (2012): 5292.

30. Sujatha, K. S., Vydeki Dharmar, and R. S. Bhuvaneswaran. "Design of genetic algorithm based IDS for MANET." 2012 International Conference on Recent Trends in Information Technology. IEEE, 2012.

31. Ouaarab, Aziz, Belaïd Ahiod, and Xin-She Yang. "Discrete cuckoo search algorithm for the travelling salesman problem." Neural Computing and Applications 24.7-8 (2014): 1659-1669.

32. Brezina Jr, Ivan, and Zuzana Čičková. "Solving the travelling salesman problem using the ant colony optimization." Management Information Systems 6.4 (2011): 10-14.

33. Pendharkar, Parag C. "An ant colony optimization heuristic for constrained task allocation problem." Journal of Computational Science 7 (2015): 37-47.

34. Choubin, Bahram, et al. "River suspended sediment modelling using the CART model: A comparative study of machine learning techniques." Science of the Total Environment 615 (2018): 272-281.

35. El-Bendary, Nashwa, et al. "Using machine learning techniques for evaluating tomato ripeness." Expert Systems with Applications 42.4 (2015): 1892-1905

36. Weiss, Ulrich, et al. "Plant species classification using a 3D LIDAR sensor and machine learning." 2010 Ninth International Conference on Machine Learning and Applications. IEEE, 2010.

37. Shekoofa, Avat, et al. "Determining the most important physiological and agronomic traits contributing to maize grain yield through machine learning algorithms: a new avenue in intelligent agriculture." PloS one 9.5 (2014): e97288.

38. Sajedi-Hosseini, Farzaneh, et al. "A novel machine learning-based approach for the risk assessment of nitrate groundwater contamination." Science of the Total Environment644 (2018): 954-962.
39. Pantazi, Xanthoula Eirini, et al. "Wheat yield prediction using machine learning and advanced sensing techniques." Computers and Electronics in Agriculture 121 (2016): 57-65.

40. Belayneh, A., et al. "Coupling machine learning methods with wavelet transforms and the bootstrap and boosting ensemble approaches for drought prediction." Atmospheric research 172 (2016): 37-47.

41. Damrongsakmethee, T., and V. E. Neagoe. "Data Mining and Machine Learning for financial analysis." Indian Journal of Science and Technology 10.39 (2017): 1-7.

42. Chopde, Ketaki, et al. "A Study of Classification Based Credit Risk Analysis Algorithm." Int J Eng Adv Technol 1.4 (2012): 142-144.

43. Lee, Ming-Chang, and Chang To. "Comparison of support vector machine and back propagation neural network in evaluating the enterprise financial distress." arXiv preprint arXiv:1007.5133 (2010).

44. Byanjankar, Ajay, Markku Heikkilä, and Jozsef Mezei. "Predicting credit risk in peer-to-peer lending: A neural network approach." Computational Intelligence, 2015 IEEE Symposium Series on. IEEE, 2015.

45. Vafeiadis, Thanasis, et al. "A comparison of machine learning techniques for customer churn prediction." Simulation Modelling Practice and Theory 55 (2015): 1-9.

46. Mori, Junichiro, et al. "Machine learning approach for finding business partners and building reciprocal relationships." Expert Systems with Applications 39.12 (2012): 1040210407.

47. Jain, Shubham, and Mark Kain. "Prediction for Stock Marketing Using Machine Learning." International Journal on Recent and Innovation Trends in Computing and Communication 6.4 (2018): 131-135.

48. Hegazy, Osman, Omar S. Soliman, and Mustafa Abdul Salam. "A machine learning model for stock market prediction." arXiv preprint arXiv:1402.7351 (2014).

49. Wang, Nanxi. "Bankruptcy Prediction Using Machine Learning." Journal of Mathematical Finance 7.04 (2017): 908.

50. Ghazanfar, Mustansar Ali, et al. "Using machine learning classifiers to predict stock exchange index." International Journal of Machine Learning and Computing 7.2 (2017): 24-29.

51. He, Yuqinq, Kamaladdin Fataliyev, and Lipo Wang. "Feature selection for stock market analysis." International Conference on Neural Information Processing. Springer, Berlin, Heidelberg, 2013.

52. Aulck, Lovenoor, et al. "Predicting student dropout in higher education." arXiv preprint arXiv:1606.06364 (2016). 
53. Kotsiantis, S., Kiriakos Patriarcheas, and $\mathrm{M}$. Xenos. "A combinational incremental ensemble of classifiers as a technique for predicting students' performance in distance education." Knowledge-Based Systems 23.6 (2010): 529-535.

54. Thangavel, Sentkil Kumar, P. Divya Bkaratki, and Abijitk Sankar. "Student placement analyzer: A recommendation system using machine learning." 2017 4th International Conference on Advanced Computing and Communication Systems (ICACCS). IEEE, 2017.

55. A.Pavithra, S.Dhanaraj. "Prediction Accuracy on Academic Performance of Students Using Different Data Mining Algorithms with Influencing Factors." International Journal of Scientific Research in Computer Science Applications and Management Studies. 7.5 (2018).; 1-7.

56. Peña-Ayala, Alejandro. "Educational data mining: A survey and a data mining-based analysis of recent works." Expert systems with applications 41.4 (2014): 1432-1462.

57. Senanayaka, Jagath Sri Lal, et al. "Early detection and classification of bearing faults using support vector machine algorithm." 2017 IEEE Workshop on Electrical Machines Design, Control and Diagnosis (WEMDCD). IEEE, 2017.

58. Zhang, Zhien, et al. "Machine learning predictive framework for $\mathrm{CO} 2$ thermodynamic properties in solution." Journal of CO2 Utilization 26 (2018): 152-159.

59. Lowe, Edward W., et al. "Comparative analysis of machine learning techniques for the prediction of logP." 2011 IEEE Symposium on Computational Intelligence in Bioinformatics and Computational Biology (CIBCB). IEEE, 2011.

60. Malhotra, Ruchika, and Ankita Jain. "Fault prediction using statistical and machine learning methods for improving software quality." Journal of Information Processing Systems8.2 (2012): 241-262.

61. Oliveira, Adriano LI, et al. "GA-based method for feature selection and parameters optimization for machine learning regression applied to software effort estimation." information and Software Technology 52.11 (2010): 1155-1166.

62. Vanaja, S., and K. Rameshkumar. "Performance analysis of classification algorithms on the medical diagnoses-a survey." Journal of Computer Science 11.1 (2015): 30-52.

63. Sriram, Tarigoppula VS, et al. "Intelligent Parkinson disease prediction using machine learning algorithms." Int. J. Eng. Innov. Technol 3 (2013): 212-215.

64. Gupta, Deepa, Sangita Khare, and Ashish Aggarwal. "A method to predict diagnostic codes for chronic diseases using machine learning techniques." 2016 International Conference on Computing, Communication and Automation (ICCCA). IEEE, 2016.

65. Nilashi, Mehrbakhsh, et al. "An analytical method for diseases prediction using machine learning techniques." Computers \& Chemical Engineering 106 (2017): 212-223.

66. Ghumbre, Shashikant, Chetan Patil, and Ashok Ghatol. "Heart disease diagnosis using support vector machine." International conference on computer science and information technology (ICCSIT') Pattaya. 2011.

67. Sartakhti, Javad Salimi, Mohammad Hossein Zangooei, and Kourosh Mozafari. "Hepatitis disease diagnosis using a novel hybrid method based on support vector machine and simulated annealing (SVM-SA)." Computer methods and programs in biomedicine 108.2 (2012): 570-579.

68. Das, T. K. "A customer classification prediction model based on machine learning techniques." 2015 International Conference on Applied and Theoretical Computing and Communication Technology (iCATccT). IEEE, 2015.

69. Patel, Jigar, et al. "Predicting stock and stock price index movement using trend deterministic data preparation and machine learning techniques." Expert Systems with Applications 42.1 (2015): 259-268.

70. Sharma, Seema, Jitendra Agrawal, and Sanjeev Sharma. "Classification through machine learning technique: C4. 5 algorithm based on various entropies." International Journal of Computer Applications 82.16 (2013).

71. Pal, Saurabh. "Mining educational data to reduce dropout rates of engineering students." International Journal of Information Engineering and Electronic Business 4.2 (2012): 1.

72. Kara, Yakup, Melek Acar Boyacioglu, and Ömer Kaan Baykan. "Predicting direction of stock price index movement using artificial neural networks and support vector machines: The sample of the Istanbul Stock Exchange." Expert systems with Applications 38.5 (2011): 53115319.

73. Guido, Gianluigi, et al. "Targeting direct marketing campaigns by neural networks." Journal of Marketing Management 27.9-10 (2011): 992-1006.

74. Emami, N., and A. Pakzad. "A New KnowledgeBased System for Diagnosis of Breast Cancer by a combination of the Affinity Propagation and Firefly Algorithms." Journal of AI and Data Mining 7.1 (2019): 59-68.

75. Rajathi, G., and G. Jiji. "Chronic Liver Disease Classification Using Hybrid Whale Optimization 
with Simulated Annealing and Ensemble Classifier." Symmetry 11.1 (2019): 33.

76. Prabukumar, M., L. Agilandeeswari, and K. Ganesan. "An intelligent lung cancer diagnosis system using cuckoo search optimization and support vector machine classifier." Journal of Ambient Intelligence and Humanized Computing (2017): 1-27.

77. Sharma, Prerna, et al. "Diagnosis of Parkinson's disease using modified grey wolf optimization." Cognitive Systems Research 54 (2019): 100-115.

78. Benmessahel, Ilyas, Kun Xie, and Mouna Chellal. "A new evolutionary neural networks based on intrusion detection systems using multiverse optimization." Applied Intelligence(2017): 1-13.

79. Sawhney, Ramit, Puneet Mathur, and Ravi Shankar. "A firefly algorithm based wrapperpenalty feature selection method for cancer diagnosis." International Conference on Computational Science and Its Applications. Springer, Cham, 2018.

80. Sharma, Prerna, et al. "The health of things for classification of protein structure using improved grey wolf optimization." The Journal of Supercomputing (2018): 1-16.

81. Wang, Hui, et al. "A new dynamic firefly algorithm for demand estimation of water resources." Information Sciences 438 (2018): 95106.

82. Chithra, R. S., and P. Jagatheeswari. "Fractional crow search-based support vector neural network for patient classification and severity analysis of tuberculosis." IET Image Processing 13.1 (2018): 108-117.

83. Gupta, Deepak, et al. "Improved diagnosis of Parkinson's disease using optimized crow search algorithm." Computers \& Electrical Engineering 68 (2018): 412-424.

84. Sayed, Gehad Ismail, Aboul Ella Hassanien, and Ahmad Taher Azar. "Feature selection via a novel chaotic crow search algorithm." Neural computing and applications 31.1 (2019): 171188.

85. Arabasadi, Zeinab, et al. "Computer aided decision making for heart disease detection using hybrid neural network-Genetic algorithm." Computer methods and programs in biomedicine 141 (2017): 19-26.

86. Mostafa, Abdalla, et al. "Antlion optimization based segmentation for MRI liver images." International Conference on Genetic and Evolutionary Computing. Springer, Cham, 2016.

87. Zamani, Hoda, and Mohammad-Hossein Nadimi-Shahraki. "Feature selection based on whale optimization algorithm for diseases diagnosis." International Journal of Computer
Science and Information Security 14.9 (2016): 1243.

88. Reddy, Gadekallu Thippa, and Neelu Khare. "Hybrid Firefly-Bat Optimized Fuzzy Artificial Neural Network Based Classifier for Diabetes Diagnosis." International Journal of Intelligent Engineering and Systems 10.4 (2017): 18-27.

89. Mostafa, Abdalla, et al. "Artificial Bee colony based segmentation for CT liver images." Medical Imaging in Clinical Applications. Springer, Cham, 2016. 409-430.

90. Elhariri, Esraa, Nashwa El-Bendary, and Aboul Ella Hassanien. "A hybrid classification model for EMG signals using grey wolf optimizer and SVMs." The 1st International Conference on Advanced Intelligent System and Informatics (AISI2015), November 28-30, 2015, Beni Suef, Egypt. Springer, Cham, 2016.

91. Chao, Chih-Feng, and M. Horng. "Firefly algorithm for training the radial basis function network in ultrasonic supraspinatus image classification." Computer Modelling \& New Technologies 18.3 (2014): 77-83.

92. Mokeddem, Sidahmed, Baghdad Atmani, and Mostéfa Mokaddem. "Supervised feature selection for diagnosis of coronary artery disease based on genetic algorithm." arXiv preprint arXiv:1305.6046 (2013).

93. Won, Chaehwan, Jinhwa Kim, and Jae Kwon Bae. "Using genetic algorithm based knowledge refinement model for dividend policy forecasting." Expert Systems with Applications39.18 (2012): 13472-13479.

94. Amma, NG Bhuvaneswari. "Cardiovascular disease prediction system using genetic algorithm and neural network." 2012 International Conference on Computing, Communication and Applications. IEEE, 2012.

95. Ephzibah, E. P. "Cost effective approach on feature selection using genetic algorithms and fuzzy logic for diabetes diagnosis." arXiv preprint arXiv:1103.0087 (2011).

96. Ganji, Mostafa Fathi, and Mohammad Saniee Abadeh. "A fuzzy classification system based on Ant Colony Optimization for diabetes disease diagnosis." Expert Systems with Applications 38.12 (2011): 14650-14659.

97. Li, Xianfeng, and Zhong Chen. "Weed identification based on shape features and ant colony optimization algorithm." 2010 International Conference on Computer Application and System Modeling (ICCASM 2010). Vol. 1. IEEE, 2010.

98. Anbarasi, M., E. Anupriya, and N. C. S. N. Iyengar. "Enhanced prediction of heart disease with feature subset selection using genetic algorithm." International Journal of Engineering Science and Technology 2.10 (2010): 5370-5376. 
99. Mannini, Andrea, and Angelo Maria Sabatini. "Machine learning methods for classifying human physical activity from on-body accelerometers." Sensors 10.2 (2010): 11541175.

100.Frantzidis, Christos A., et al. "On the classification of emotional biosignals evoked while viewing affective pictures: an integrated data-mining-based approach for healthcare applications." IEEE Transactions on Information Technology in Biomedicine 14.2 (2010): 309318.

101.Son, Youn-Jung, et al. "Application of support vector machine for prediction of medication adherence in heart failure patients." Healthcare informatics research 16.4 (2010): 253-259.

102.Rajkumar, Asha, and G. Sophia Reena. "Diagnosis of heart disease using datamining algorithm." Global journal of computer science and technology 10.10 (2010): 38-43.

103. Mwebaze, Ernest, and Godliver Owomugisha. "Machine learning for plant disease incidence and severity measurements from leaf images." 2016 15th IEEE International Conference on Machine Learning and Applications (ICMLA). IEEE, 2016.

104.Ulissi, Zachary W., et al. "Machine-learning methods enable exhaustive searches for active bimetallic facets and reveal active site motifs for CO2 reduction." ACS Catalysis 7.10 (2017): 6600-6608.

105.Li, Hao, et al. "Predictive power of machine learning for optimizing solar water heater performance: the potential application of highthroughput screening." International journal of photoenergy 2017 (2017).

106. Sharma, M., G. Singh, and R. Singh. "An Advanced Conceptual Diagnostic Healthcare Framework for Diabetes and Cardiovascular Disorders." arXiv preprint arXiv:1901.10530 (2019).

107.Zhang, Zhien, et al. "Machine learning predictive framework for $\mathrm{CO} 2$ thermodynamic properties in solution." Journal of CO2 Utilization 26 (2018): 152-159.

108.Senders, Joeky T., et al. "An introduction and overview of machine learning in neurosurgical care." Acta neurochirurgica160.1 (2018): 29-38.

109. Sharma, Manik, Samriti Sharma, and Gurvinder Singh. "Performance Analysis of Statistical and Supervised Learning Techniques in Stock Data Mining." Data 3.4 (2018): 54.

110.Nadjemi, O., et al. "Optimal hybrid PV/wind energy system sizing: Application of cuckoo search algorithm for Algerian dairy farms." Renewable and Sustainable Energy Reviews 70 (2017): 1352-1365. 